\section{PAM: A double-precision FORTRAN routine for the parallel analysis method in principal components analysis}

R. STEWART LONGMAN, ALBERT A. COTA, RONALD R. HOLDEN, and G. CYNTHIA FEKKEN Queen's University, Kingston, Ontario, Canada

Parallel analysis (Horn, 1965) is a Monte Carlo method of establishing the number of components in principal components analysis, and suggests retention of only those components from observed data whose eigenvalues are larger than the corresponding eigenvalues from random data. It can be seen as a correction of the eigenvalue-one rule for sample, rather than population, characteristics. PAM is a mainframe computer program that implements the parallel analysis method by providing mean and upperpercentile eigenvalues from multiple replications of random data.

Both Monte Carlo studies (e.g., Zwick \& Velicer, 1986) and studies with established data sets (e.g., Hubbard \& Allen, 1987) have found that parallel analysis yields accurate results. Unfortunately, parallel analysis is not widely used, because at least one replication of random data must be generated. Typically, eigenvalues from several replications of random data are averaged for each ordinal position to provide criterion eigenvalues, which are then compared to observed eigenvalues.

To increase the accessibility of parallel analysis for researchers, regression equations have been developed to predict mean expected eigenvalues from random data (Allen \& Hubbard, 1986; Lautenschlager, Lance, \& Flaherty, 1989; Longman, Cota, Holden, \& Fekken, 1989). As well, Longman et al. (1989) provide regression weights for predicting 95th-percentile eigenvalues from random data. This is suggested as a potential remedy for the tendency of parallel analysis to overestimate slightly the number of components to retain (Lautenschlager, in press; Zwick \& Velicer, 1986). These regression equations have been implemented in microcomputer programs, which calculate expected eigenvalues (e.g., Hays, 1987; Holden, Longman, Cota, \& Fekken, in press).

There are drawbacks to the use of regression strategies, however. First, they yield only estimates of criterion

Preparation of this paper was supported by the Medical Research Council of Canada, the Social Sciences and Humanities Research Council of Canada, and the Ontario Ministry of Health. Computing facilities and assistance were provided by Computing and Communications Services at Queen's University. We gratefully acknowledge comments made by two anonymous reviewers on a previous draft. Program listings may also be obtained from the first author via BITNET, at LONGMANR@QUCDN. Address correspondence to R. Stewart Longman, Department of Psychology, Queen's University, Kingston, Ontario K7L 3N6, Canada. eigenvalues. Second, they are valid for only a limited range of subjects and variables (e.g., no equations exist for applications of principal components analysis with more than 50 variables or 1,000 subjects). Third, there are conditions under which both the Allen and Hubbard (1986) procedure and the Lautenschlager et al. (1989) procedure yield anomalous results for applications within the nominal range of these techniques (Cota, Longman, Holden, \& Fekken, 1989; Lautenschlager, in press; Longman et al., 1989).

PAM is a mainframe program that circumvents these deficiencies. Designed for parallel analysis of principal components, it calculates both mean and upper-percentile eigenvalues from a specified number of correlation matrices generated directly from random normal deviates. The procedure eliminates regression errors, and calculations are done in double-precision arithmetic to minimize rounding errors. Moreover, PAM does not restrict the number of subjects and variables that can be specified. Because it can be set to perform any number of replications, 95th- or other upper-percentile eigenvalues can be calculated for specified subject and variable parameters. As mentioned above, this may be more useful than relying solely on mean eigenvalues.

Program description. PAM is a mainframe computer program written in VS FORTRAN, using double-precision subroutines from IMSL version 10 (International Mathematical and Statistical Libraries, 1987). If necessary, subroutines from other sources (e.g., Numerical Algorithms Group, 1984) could be substituted for those from IMSL. As well, PAM can be implemented using the microcomputer versions of the IMSL subroutines described in the listing. Caution is advised on implementing PAM with microcomputers, however; even powerful microcomputers may take a great deal of time to complete Monte Carlo simulations (Lautenschlager, in press), and mainframe implementation may be more convenient.

Limitations. Two limitations exist for this program. First, the magnitude of eigenvalues from random data is constrained by the distribution of those data (Fang \& Krishnaiah, 1982). Because the random number generator currently provides random normal deviates, only data from multivariate normal or near-normal distributions should be compared with the output from PAM as implemented here. If the data being compared have substantially nonnormal distributions, some similarly distributed source of random numbers should be used (Armstrong \& Soelberg, 1968). IMSL version 10 has routines that can generate random data from a variety of distributions (e.g., RNLNL for log-normal distributions, or RNUN for uniform distributions). Second, when the number of subjects is less than the number of variables, inaccurate or anomalous results may occur. These results, of course, may also emerge with actual data when there are more variables than subjects. 
Table 1

Example with 50 Subjects and 10 Variables

\begin{tabular}{|c|c|c|c|c|c|c|c|}
\hline \multirow{3}{*}{$\frac{\text { Item }}{1}$} & \multicolumn{7}{|c|}{ Source of Eigenvalues } \\
\hline & \multirow{2}{*}{$\begin{array}{c}\begin{array}{c}\text { Observed } \\
\text { Data }\end{array} \\
4.336\end{array}$} & \multicolumn{2}{|c|}{$\begin{array}{c}\text { PAM } \\
(100 \text { trials }) \\
\text { Mean 95th Percentile }\end{array}$} & \multicolumn{2}{|c|}{$\begin{array}{c}\text { PAM } \\
(1,000 \text { trials }) \\
\text { Mean 95th Percentile }\end{array}$} & \multicolumn{2}{|c|}{$\begin{array}{c}\text { Regression* } \\
\text { Mean 95th Percentile }\end{array}$} \\
\hline & & 1.785 & 2.017 & 1.779 & 2.020 & 1.753 & 1.975 \\
\hline 2 & 1.484 & 1.510 & 1.700 & 1.512 & 1.668 & 1.501 & 1.647 \\
\hline 3 & 1.042 & 1.335 & 1.458 & 1.314 & 1.442 & 1.319 & 1.432 \\
\hline 4 & 0.756 & 1.166 & 1.261 & 1.156 & 1.260 & 1.134 & 1.233 \\
\hline 5 & 0.729 & 1.010 & 1.115 & 1.020 & 1.114 & 1.010 & 1.097 \\
\hline 6 & 0.439 & 0.873 & 0.966 & 0.888 & 0.982 & 0.896 & 0.979 \\
\hline 7 & 0.423 & 0.760 & 0.853 & 0.764 & 0.859 & 0.788 & 0.869 \\
\hline 8 & 0.341 & 0.638 & 0.759 & 0.644 & 0.734 & 0.686 & 0.765 \\
\hline 9 & 0.262 & 0.526 & 0.621 & 0.524 & 0.617 & & \\
\hline 10 & 0.188 & 0.397 & 0.484 & 0.398 & 0.498 & & \\
\hline
\end{tabular}

*These values were derived from the Longman et al. (1989) regression procedure. Eigenvalues for the last two ordinal positions should not be estimated when using this procedure.

Program listing and sample output. In the program listing provided in the Appendix, PAM is set up to run an analysis with 50 subjects, 10 variables, and 100 replications, and to output mean and 95th-percentile eigenvalues. Any of these values may be changed by replacing the current values with the preferred values, as described in the program comments. We recommend that PAM first be run to these specifications (including the same seed for the random number generator), and the output compared to Table 1 to ensure proper implementation.

Results from PAM with 100 and 1,000 replications, and from a regression equation (Longman et al., 1989), are shown in Table 1, along with actual eigenvalues derived from 50 subjects' responses to a 10 -item handedness questionnaire. Using both mean and 95th-percentile criterion eigenvalues, all three methods converge to indicate that only one component should be retained, because only the first eigenvalue from the observed data is greater than the corresponding eigenvalue from random data. In this example, PAM (100 replications) is slightly (although not significantly) more accurate than the regression method in predicting the eigenvalues based on 1,000 replications.

\section{REFERENCES}

Allen, S. J., \& HubBard, R. (1986). Regression equations for the latent roots of random data correlation matrices with unities on the diagonal. Multivariate Behavioral Research, 21, 393-398.

Armstrong, J. S., \& Soelberg, P. (1968). On the interpretation of factor analysis. Psychological Bulletin, 70, 361-364.
Cota, A. A., Longman, R. S., Holden, R. R., * Fekken, G. C. (1989). Anomalies in Allen and Hubbard's procedure for parallel analysis. Unpublished manuscript.

Fang, C., \& Kishnaiah, P. R. (1982). Asymptotic distributions of functions of the eigenvalues of some random matrices for nonnormal populations. Journal of Multivariate Analysis, 12, 39-63.

HAYS, R. (1987). PARALLEL: A program for performing parallel analysis. Applied Psychological Measurement, 11, 58.

Holden, R. R., Longman, R. S., Cota, A. A., \& Fekken, G. C. (in press). PAR: Parallel analysis routine for random data eigenvalue estimation. Applied Psychological Measurement.

HoRN, J. L. (1965). A rationale and test for the number of factors in factor analysis. Psychometrika, 30, 179-185.

HubBard, R., * Allen, S. J. (1987). An empirical comparison of alternative methods for principal component extraction. Journal of Business Research, 15, 173-190.

INTERNational Mathematical and Statistical Libraries. (1987). Intemational Mathematical and Statistical Libraries reference manual (10th ed.). Houston: Author.

LAUTENSCHLAGER, G. J. (in press). A comparison of alternatives to conducting Monte Carlo analyses for determining parallel analysis criteria. Multivariate Behavioral Research.

Lautenschlager, G. J., Lance, C. E., \& Flaherty, V. L. (1989). Parallel analysis criteria: Revised equations for estimating the latent roots of random data correlation matrices. Educational \& Psychological Measurement, 49, 339-345.

Longman, R. S., Cota, A. A., Holden, R. R., \& Fekken, G. C. (1989). A regression equation for the parallel analysis criterion in principal components analysis: Mean and 95th percentile eigenvalues. Multivariate Behavioral Research, 24, 59-69.

Numerical Algorithms Group (1984). FORTRAN Library Manual, Mark 11. Downers Grove, IL: Author.

ZWICK, W. R., \& VELICER, W. F. (1986), Comparison of five rules for determining the number of components to retain. Psychological Bulletin, 99, 432-442.

APPENDIX

Program Listing

C 'NV' IS NUMBER OF VARIABLES 'NS' IS NUMBER OF SUBJECTS
$C$ 'I' IS NUMBER OF TRIALS (REPLICATIONS) USED
INTEGER NV, NS, I, NF
C THE USER MUST PROVIDE THE VALUES OF NV, NS, AND I BELOW
PARAMETER (NV=10, NS=50, I=100)


C THE USER SHOULD SET NF AT THE APPROPRIATE LEVEL

C (E.G. 95 IF 100, OR 19 IF 20 TRIALS)

C NF MUST BE LESS THAN I

PARAMETER $(\mathrm{NF}=95)$

C OUTPUT IS SENT TO UNIT 7. THIS MUST BE DEFINED BEFORE RUNNING PAM. DOUBLE PRECISION R(NV,NV), S(NV), D(NV), A(I,NV), C(I)

DOUBLE PRECISION $X(N S, N V), X M(N V)$, MEAN(NV) DIMENSION Y (NS)

C THE USER CAN SET ISEED TO ANY NON-NEGATIVE INTEGER ISEED $=973$

C SETTING THE SEED FOR RANDOM NUMBER GENERATOR USING RNSET CALL RNSET (ISEED)

DO $40 \mathrm{~L}=1, \mathrm{I}$ DO $20 \mathrm{~K}=1, \mathrm{NV}$

C GENERATING MATRIX OF RANDOM NORMAL DEVIATES USING RNNOA CALL RNNOA (NS, Y)

DO $10 \mathrm{~J}=1$, NS

$X(J, K)=\operatorname{DBLE}(\mathrm{Y}(\mathrm{J}))$

10 CONTINUE

20 CONTINUE

C GENERATING AN (NV BY NV) CORRELATION MATRIX USING DCORVC CALL DCORVC $(0, N S, N V, X, N S, 0,0,0,2, X M, R, N V, I X, 1, I B, I C, I D)$

C FINDING THE EIGENVALUES OF THE CORRELATION MATRIX USING DEVLSF

CALL DEVLSF (NV, R,NV,D)

DO $30 \mathrm{~K}=1, \mathrm{NV}$

$A(L, K)=D(K)$

30 CONTINUE

40 CONTINUE

DO $70 \mathrm{~K}=1, \mathrm{NV}$

DO $50 \mathrm{~L}=1, \mathrm{I}$

$C(L)=A(L, K)$

50 CONTINUE

C SORTING EIGENVALUES USING DSVRGN; UPPER PERCENTILES FOUND THIS WAY

CALL DSVRGN $(I, C, C)$

DO $60 \mathrm{~L}=1, \mathrm{I}$

$A(L, K)=C(L)$

60 CONTINUE

70 CONTINUE

DO $110 \mathrm{~K}=1$, NV

$\operatorname{MEAN}(K)=0$.

DO $100 \mathrm{~J}=1, I$

$\operatorname{MEAN}(K)=\operatorname{MEAN}(K)+A(J, K)$

100 CONTINUE

$\operatorname{MEAN}(\mathrm{K})=\operatorname{MEAN}(\mathrm{K}) / \mathrm{I}$

110 CONTINUE

WRITE $(7,65)$ NS, NV, I

WRITE $(7,75)$

WRITE $(7,85) \quad(\operatorname{MEAN}(K), K=N V, 1,-1)$

WRITE $(7,95) \quad N F, I$ 


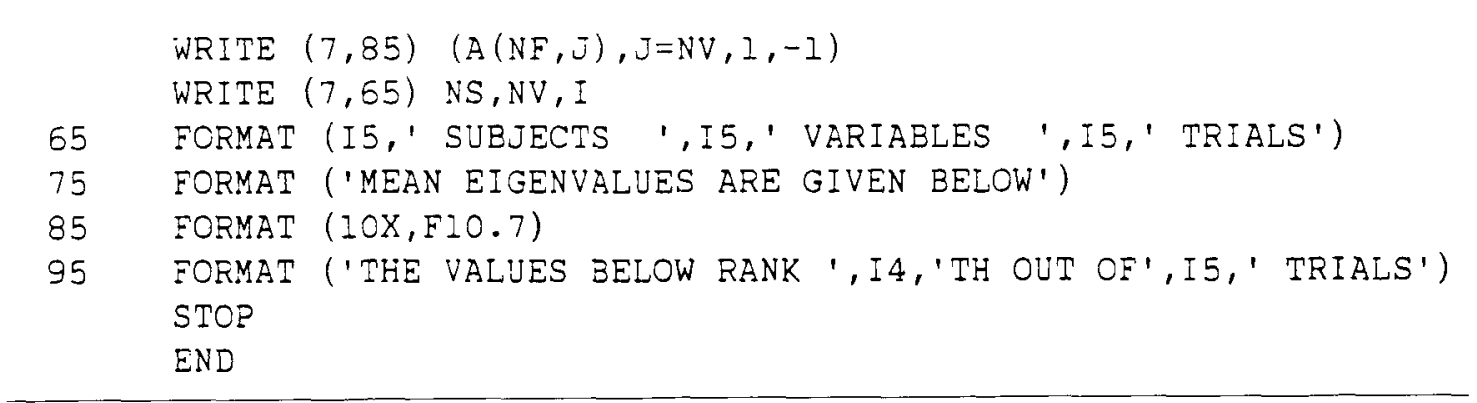

(Manuscript received March 14, 1989;

revision accepted for publication June 19, 1989.) 